\title{
Eosinophilic esophagitis, Barrett's esophagus and esophageal neoplasms in the pediatric patient: a narrative review
}

\author{
Annette L. Medina ${ }^{1}$, David M. Troendle ${ }^{1}$, Jason Y. Park ${ }^{2}$, Ameet Thaker ${ }^{2}$, Kerry B. Dunbar ${ }^{3}$, Edaire Cheng ${ }^{1}$ \\ ${ }^{1}$ Division of Pediatric Gastroenterology, Hepatology, and Nutrition, Department of Pediatrics, ${ }^{2}$ Department of Pathology, Children's Health \\ Medical Center, University of Texas Southwestern Medical Center, Dallas, TX, USA; ${ }^{3}$ Division of Gastroenterology and Hepatology, Department of \\ Medicine, Esophageal Diseases Center, Dallas VA Medical Center, VA North Texas Healthcare System, University of Texas Southwestern Medical \\ Center, Dallas, TX, USA \\ Contributions: (I) Conception and design: None; (II) Administrative support: None; (III) Provision of study materials or patients: None; (IV) \\ Collection and assembly of data: None; (V) Data analysis and interpretation: None; (VI) Manuscript writing: All authors; (VII) Final approval of \\ manuscript: All authors. \\ Correspondence to: Edaire Cheng, MD. Division of Pediatric Gastroenterology, Hepatology, and Nutrition, Department of Pediatrics, Children's Health \\ Medical Center, University of Texas Southwestern Medical Center, 5323 Harry Hines Boulevard, Dallas, TX 75390, USA. \\ Email: Edaire.Cheng@utsouthwestern.edu.
}

\begin{abstract}
There are several esophageal disorders that can occur in the pediatric population. Eosinophilic esophagitis (EoE) is an eosinophil predominant inflammatory disease of the esophagus that was first characterized in the early 1900's. EoE is the most common pediatric esophageal inflammatory condition after gastroesophageal reflux disease (GERD). Longstanding GERD is a known risk factor for the development of Barrett's esophagus (BE) in both children and adults. BE is associated with the development of dysplasia and, if left undiagnosed, may progress to the development of esophageal adenocarcinoma (EAC). EAC and esophageal squamous cell carcinoma (ESCC) comprise the majority of childhood esophageal malignant neoplasms. The prevalence of EoE continues to rise within the pediatric population. On the other hand, both $\mathrm{BE}$ and esophageal neoplasms remain extremely rare in children. The relationship between a chronic inflammatory condition like EoE to $\mathrm{BE}$ and/or esophageal neoplasms remains unclear. The current research of these disease entities is prioritized to further understanding the disease pathogenesis and disease progression, exploring new diagnostic modalities, and developing novel treatments or less invasive therapeutic options. The focus of the following narrative review is to provide a summary of the current clinical practices, future research and their implications on these various esophageal disorders.
\end{abstract}

Keywords: Barrett's esophagus (BE); eosinophilic esophagitis (EoE); esophageal adenocarcinoma (EAC); esophageal cancer

Received: 15 May 2020; Accepted: 31 July 2020; Published: 25 July 2021.

doi: $10.21037 /$ tgh-20-223

View this article at: http://dx.doi.org/10.21037/tgh-20-223

\section{Introduction}

Several esophageal disorders occur in the pediatric population. Eosinophilic esophagitis (EoE) is the most common pediatric esophageal inflammatory condition after gastroesophageal reflux disease (GERD). EoE is an eosinophil-predominant inflammatory disease of the esophagus that affects both pediatric and adult populations.
Although clinical presentation and endoscopic features of EoE may vary between both populations, similarities do exist. These similarities include the association with atopic conditions, underlining pathogenesis and disease complications. The relationship between GERD and EoE is quite complex and will not be covered in this narrative review. However, longstanding GERD is a known risk factor for the development of Barrett's esophagus (BE) in 
both adults and children. $\mathrm{BE}$ is associated with development of dysplasia and, if left undiagnosed, may progress to esophageal adenocarcinoma (EAC). The prevalence of EoE is increasing in the pediatric population. On the other hand, both $\mathrm{BE}$ and esophageal neoplasms remain extremely rare in children.

Current research of these disease entities is prioritized to understanding disease pathogenesis and progression, new diagnostic modalities, and developing novel therapeutic options. In this narrative review, we will examine the current epidemiology, clinical practices and recent research and their implications on future practices.

We present the following article in accordance with the Narrative Review reporting checklist (available at http:// dx.doi.org/10.21037/tgh-20-223).

\section{Methods}

We conducted a literature review search on PubMed and MEDLINE using the terms "Pediatric", "Barrett's Esophagus" "Eosinophilic esophagitis", "esophageal adenocarcinoma" and "esophageal cancer" from January 1989 through April 2020.

\section{Eosinophilic esophagitis}

\section{Epidemiology and clinical presentation}

EoE involves antigen-mediated eosinophilic inflammation of the esophagus leading to esophageal dysfunction and clinical symptoms (1-5). In the United States, the prevalence of EoE is estimated at 57 per 100,000 with a male predominance of 3:1 (4,6,7). EoE affects all racial and ethnic groups, with increased prevalence in Caucasians $(2,3,6)$.

Age-related differences in the clinical presentation of EoE in children and adults are appreciated $(4,8)$. In younger children, symptoms include emesis, abdominal pain, nausea, reflux, feeding dysfunction, and failure to thrive $(4,9)$. Feeding difficulties may present as dysphagia, food aversion, choking, gagging, or food impaction (10). Solid food dysphagia is the most common presenting symptom in adolescents and adults, and as many as $50 \%$ of adults initially present with food impaction $(2,4)$. For this reason, an adolescent or adult with food impaction warrants further diagnostic evaluation for $\mathrm{EoE}$ (8). Other symptoms displayed in adults include reflux, chest discomfort, and upper abdominal pain $(4,11)$. Atopic comorbidities, including asthma, allergic rhinitis, atopic dermatitis, and food allergies, are common (70-80\%) in pediatric patients with $\operatorname{EoE}(2,5)$.

\section{Diagnosis}

EoE is a clinicopathologic disease, requiring both clinical and histologic findings consistent with the diagnosis. Thus, endoscopic evaluation by esophagogastroduodenoscopy (EGD) with esophageal mucosal biopsies is necessary. Endoscopic features suggestive of EoE include presence of edema, fixed esophageal rings, white exudates, linear longitudinal furrowing, mucosal fragility, and esophageal narrowing (Figure 1) $(5,12)$. In the pediatric EoE population, inflammatory endoscopic features of edema, exudates, and furrowing are more common (4). Features may also be subtle and in some cases, the esophageal mucosa is normal in appearance $(4,13)$. Progressive disease with chronic inflammation can lead to esophageal remodeling, which can lead to fibrostenotic endoscopic features such as rings, strictures, narrowing, and mucosal tears (10-12). On histology, findings of esophageal intraepithelial eosinophilia ( $\geq 15$ eosinophils/high power field), basal cell hyperplasia, elongation of vascular papillae, intercellular edema (spongiosis), and degranulation of eosinophils are findings consistent with active EoE disease (Figure 2) (2,5,8,10,14-16). Pathologists can also identify subepithelial fibrosis when there is sufficient lamina propria in biopsy specimens (16). Histopathologic changes in EoE can be patchy; therefore multiple biopsies obtained from three levels (i.e., proximal, middle, and distal) of the esophagus are recommended to maximize diagnostic yield of $\mathrm{EoE}$ and to detect subepithelial fibrosis (16).

Both the diagnosis and management of EoE are dependent on mucosal biopsy for accurate diagnosis and to assess the response to therapy. Mucosal evaluation is most commonly performed by EGD. Less invasive modalities for monitoring EoE disease activity and response to therapy are being investigated. The Esophageal String Test (EST) is a minimally invasive technique that utilizes the Enterotest string device which is a gelatin capsule containing a nylon string that is swallowed and later withdrawn through the mouth. EST can detect active EoE inflammation by measuring biomarkers such as eotaxin- 3 and major basic protein-1 $(8,17,18)$. Luminal concentrations of eosinophil- 

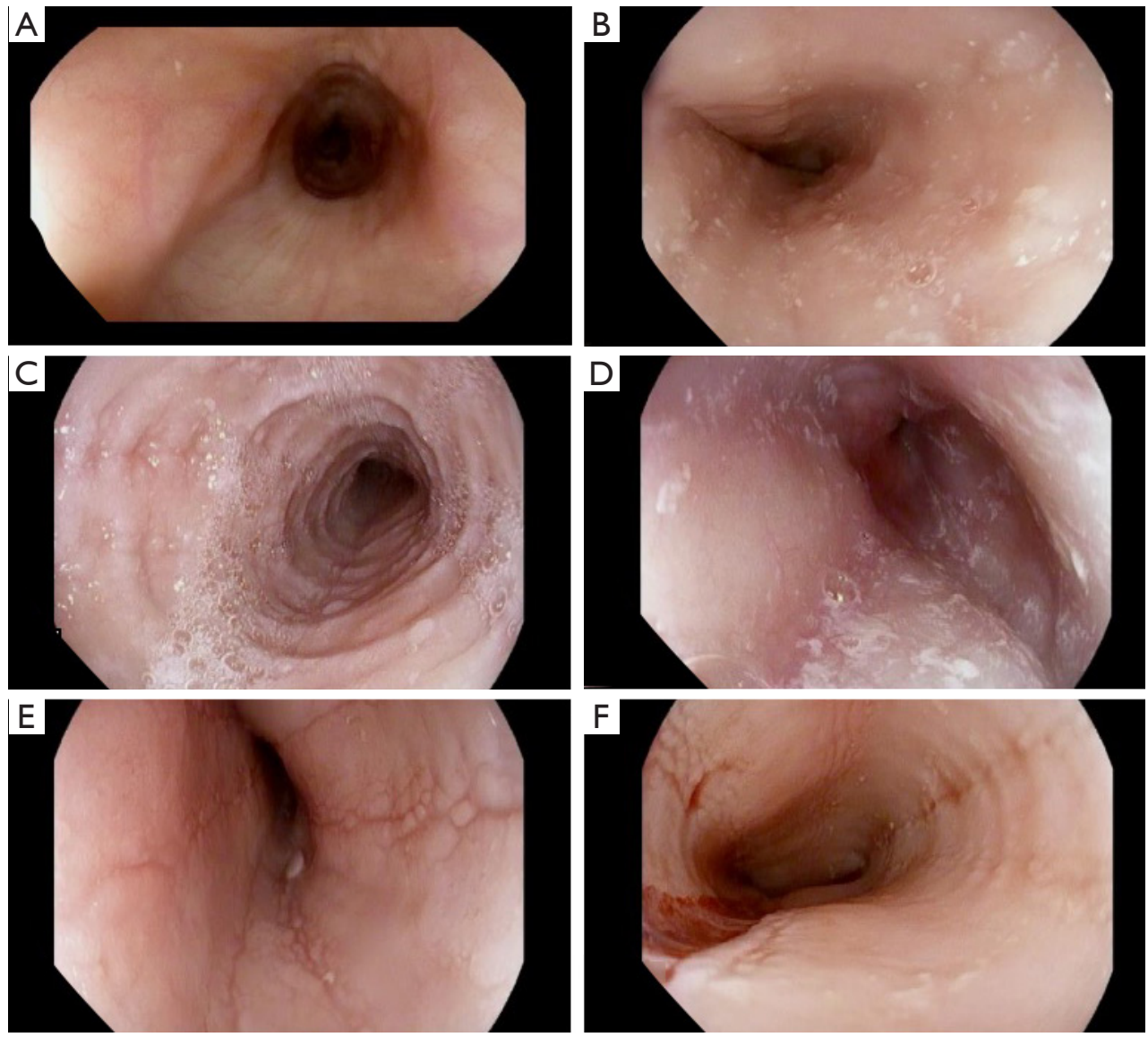

Figure 1 Endoscopic features in pediatric EoE. (A) Normal esophagus for comparison. Endoscopic features in pediatric cases with EoE include (B) esophageal mucosal edema with loss of vascular markings, (C) circumferential rings or trachealization, (D) exudates or white plaques, (E) vertical, longitudinal linear furrowing, or (F) crepe paper esophagus with mucosal fragility upon passage of the endoscope. EoE, eosinophilic esophagitis.

associated proteins obtained by EST were found to correlate with esophageal mucosal eosinophilic inflammation $(17,18)$. A prospective, multisite study evaluating 134 subjects (both pediatric and adult) by Ackerman et al. demonstrated that a 1-hour EST accurately distinguishes active $v s$. inactive EoE in a less invasive and safe manner compared to endoscopic examination with biopsies (18). Unsedated transnasal endoscopy (uTNE) utilizes a small flexible endoscope for sampling esophageal mucosa and can be performed without anesthesia or sedation in select patients. Studies in pediatrics have shown that it is an adequate, well-tolerated, and costeffective method of mucosal evaluation for monitoring disease activity in $\operatorname{EoE}(19,20)$. Currently the suitability of uTNE in pediatrics is an area under investigation by a network of academic pediatric gastroenterology centers. The Cytosponge is an encapsulated compressed mesh sponge attached to a string. Once swallowed and in the stomach, the capsule dissolves and the sponge expands. Upon withdrawing the sponge through the mouth by the attached string, cells are sampled from the esophagus $(8,21)$. Katzka et al. compared the adequacy and diagnostic accuracy of esophageal sample collection by endoscopy versus the Cytosponge in adult patients and found that samples collected by Cytosponge were adequate in evaluating epithelial activity in adult patients with EoE (21).

In contrast to the tests that sample the mucosa, the endoscopic functional luminal imaging probe (EndoFLIP) serves as an additional diagnostic modality that phenotypically characterizes EoE by assessing esophageal distensibility (i.e., 'stiffness') through the use of high resolution planimetry during endoscopy $(8,22)$. Distensibility is defined as the measure of the esophageal 


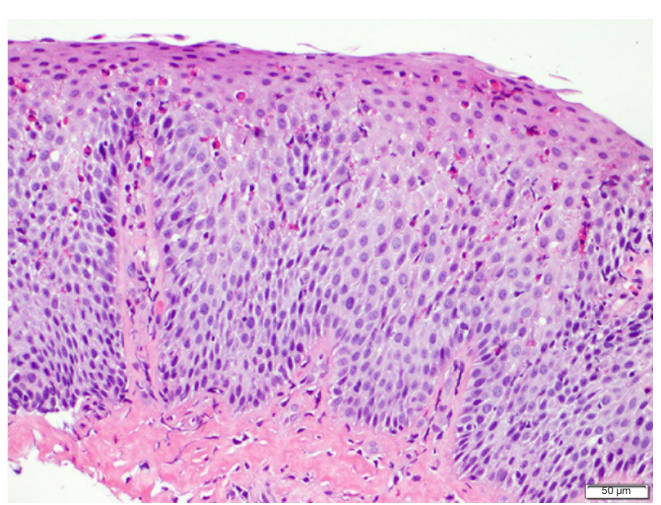

Figure 2 Histologic features of active EoE in a pediatric patient. Esophageal biopsy with evidence of intraepithelial eosinophilia ( $\geq 15$ eosinophils/high power field), spongiosis, rete papillae elongation, and basal cell hyperplasia. Subepithelial fibrosis is seen in the lamina propria (H\&E stain, $100 \times$ magnification). EoE, eosinophilic esophagitis.

luminal cross sectional area and distending pressure (23). In patients with EoE, esophageal distensibility is reduced compared to controls $(23,24)$. The EndoFLIP might serve as an adjunctive tool to assess the extent of esophageal remodeling in EoE by measuring esophageal narrowing, strictures, and rigidity (23). Although there continues to be evolving technologies for the future of diagnosis and monitoring of EoE, upper endoscopy with biopsy remains the current standard of practice.

\section{Treatment and management}

The goal of EoE treatment is to mitigate ongoing esophageal inflammation, obtain symptom resolution, achieve histological remission, and prevent further esophageal remodeling. Treatment options include topical corticosteroids, proton pump inhibitor (PPI) therapy, and dietary therapy $(14,25,26)$. However, there is no FDAapproved therapy for EoE.

Topical corticosteroids are quite effective for $\mathrm{EoE}$ and have demonstrated a disease remission rate of $50-60 \%$ $(2,27)$. The challenge with use of topical corticosteroids is ensuring effective delivery of the medication to the entire luminal surface of the esophagus (2). Currently, oral viscous budesonide slurry and swallowed aerosolized fluticasone are the most common and accepted means of administration. A multicenter Phase 3 randomized, placebo-controlled, double-blind trial in adult patients evaluated the use of a newer formulation of budesonide in patients with active EoE (28). This study demonstrated the effectiveness of an orodispersable budesonide tablet formulation in inducing clinical, histological and endoscopic remission in EoE compared to placebo ( $58 \%$ vs. $0 \%, \mathrm{P}<0.0001)$ (28).

PPI therapy has a $40-50 \%$ success rate for achieving histological remission in $\operatorname{EoE}(29,30)$. The potential antiinflammatory and antioxidant properties of PPIs are thought to contribute to its efficacy (31). PPIs have antiinflammatory properties that suppress expression of IL13 -induced-eotaxin-3, an eosinophil attractant, in the esophageal epithelium, thereby potentially reducing recruitment of eosinophils into the esophagus $(3,32,33)$. Recent EoE guidelines consider PPIs a potential early or initial therapeutic option due to their low cost, safety profile, and efficacy $(5,27,31)$.

Food allergens and aeroallergens play a role in the pathogenesis of EoE (14). Dietary modification is considered an acceptable treatment modality for EoE $(14,34)$. Three distinct dietary approaches have been utilized including the elemental diet, empiric food elimination diet, and allergy testing-directed elimination diet $(2,14,33)$. The elemental diet is restricted to an amino acid-based formula without any intact dietary protein $(14,34)$. In a systematic review analyzing the efficacy of dietary interventions in inducing EoE disease remission, an elemental diet had a near $90 \%$ success rate (35). Empiric food elimination diets exclude the most common food allergens: cow's milk, egg, soy, wheat, peanut/tree nut, and fish/shellfish (14). In children with EoE, histological remission was seen in $74 \%$ of children treated with the six-food elimination diet (36). Allergy testing-directed diet therapy was less successful, exhibiting remission in only $45 \%$ of cases (35).

Due to the chronic inflammatory nature of EoE, esophageal strictures and narrowing may result from ongoing esophageal remodeling unresponsive to treatment (37). In these cases, esophageal dilation (bougie or balloon technique) may be used in the management of fibrostenotic lesions or as adjuvant therapy to aid in clinical symptomatic relief (33,37-39). While dilation can improve areas of stenosis, it does not treat the inflammation due to esophageal eosinophilia (30).

The pathogenesis of EoE involves inflammatory infiltrates including eosinophils, T-cells, mast cells, and their chemokines and cytokines, such as interleukin (IL)-4, IL-5 and IL-3 $(33,39,40)$. Therapies have been developed to target these specific immune pathways (39). Dupilumab 
is a human monoclonal antibody against the IL-4 receptor that inhibits IL-4 and IL-13 signaling and is an effective treatment of several allergic and atopic diseases (27). In a 12 -week multicenter, randomized, double-blind, parallel group, placebo-controlled Phase 2 study of adult patients with active EoE, dupilumab reduced dysphagia and histological and abnormal endoscopic features of $\mathrm{EoE}$ compared with placebo, and was overall a well-tolerated drug (27). Participants enrolled in this study were required to remain on a stabilized diet 6 weeks before screening and throughout completion of the study. Additionally, they were prohibited to utilize concomitant medications for the treatment of EoE, immunotherapies, investigational drugs other than Dupilumab, and could not start PPI therapy unless having been using the medication in the 8 weeks before screening. Mepolizumab and reslizumab are monoclonal antibodies targeting IL-5. Despite a decrease in esophageal tissue eosinophilia with these drugs, symptomatic improvement has been inconsistent. Potential clinical benefit requires additional studies $(27,41)$. Sialic acid binding immunoglobulin-like lectins (Siglecs) are transmembrane protein receptors expressed on eosinophils. AK002, an antibody directed against Siglec 8, causes apoptosis of human eosinophils $(39,41)$. There is an ongoing phase $2 / 3$ randomized, placebo-controlled trial to assess its safety and efficacy in adolescent and adult patients with active EoE (ClinicalTrials.gov. NCT04322708). Participants in this study are excluded if they have used of oral corticosteroids within 8 weeks prior to screening, had a change in dose in PPI therapy of dietary therapy within 4 weeks prior to screening, or used immunosuppressants or immunomodulatory drugs within 12 weeks prior to screening.

\section{Barrett's esophagus}

\section{Epidemiology and clinical presentation}

$\mathrm{BE}$ is defined as the presence of metaplastic intestinaltype columnar epithelium that has replaced the normal squamous epithelium lining of the esophagus $(42,43)$. BE predominantly presents in adults, with a prevalence of $1 \%$ to $2 \%$ of all patients referred for upper endoscopy. BE is seen in approximately $5-15 \%$ of patients exhibiting symptoms of gastroesophageal reflux (GER) (44-46). The prevalence of $\mathrm{BE}$ in children varies between $0.05 \%$ to $4.8 \%$, with a mean age 12.4 years at diagnosis $(46,47)$. The main risk factor in both adults and children is longstanding GER. BE has been identified in children with reflux after a period of 5.3 years (46). Predisposing risk factors for children include tracheoesophageal abnormalities, neurological impairment, chronic lung disease, hiatal hernia, and increased body mass index in patients without underlying conditions (46,47). In adults, additional risk factors include male gender, central obesity, age over 50 years, tobacco usage, Caucasian race, and family history in a first-degree relative $(43,45,48)$.

Since pediatric $\mathrm{BE}$ is rare, there is a paucity of data to suggest that pediatric $\mathrm{BE}$ portends a worse prognosis compared to adult BE. However, as previously mentioned, studies in adults have indicated that long duration of GERD symptoms are a risk factor for BE (44-46). Furthermore, there are no specific guidelines available for screening or treatment in children with $\mathrm{BE}$. As the prevalence of pediatric BE increases, pediatric guidelines for screening and management will be warranted. Overall, practice guidelines on the diagnosis and management of $\mathrm{BE}$ in adults recommend screening in only patients that meet the identified risk factors including men with chronic reflux disease $(>5$ years) and two or more risk factors $(42,43,45)$. The American College of Gastroenterology (ACG) suggests, in women, to screen those with multiple risk factors $(42,45)$.

\section{Diagnosis}

The diagnosis of $\mathrm{BE}$ requires identification of salmon colored mucosa extending into the esophagus at least $1 \mathrm{~cm}$ proximal to the gastroesophageal junction (GEJ) combined with histological confirmation of intestinal metaplasia (IM) exemplified by the presence of goblet cells (Figure 3) (42). Biopsies from four-quadrants at $2 \mathrm{~cm}$ intervals should be obtained over the length of the $\mathrm{BE}$ segment during endoscopy $(43,45)$. If $\mathrm{BE}$ is suspected, at least eight random biopsies from the segment should be obtained in order to maximize the yield of IM on histology $(42,49)$. In the case of short segments (i.e., $<3 \mathrm{~cm}$ ) of suspected BE, at least four biopsies per cm of circumferential BE and one biopsy per $\mathrm{cm}$ in tongues of $\mathrm{BE}$ should be obtained (42). If BE is suspected, but there is lack of IM on histology, a repeat endoscopy should be considered in 1-2 years (42).

$\mathrm{BE}$ is associated with the development of EAC (43). The risk of cancer progression in BE is $0.2-0.5 \%$ per year in patients with nondysplastic changes and up to approximately $6 \%$ per year in patients with evidence of high-grade dysplasia (42). The goal of endoscopic 

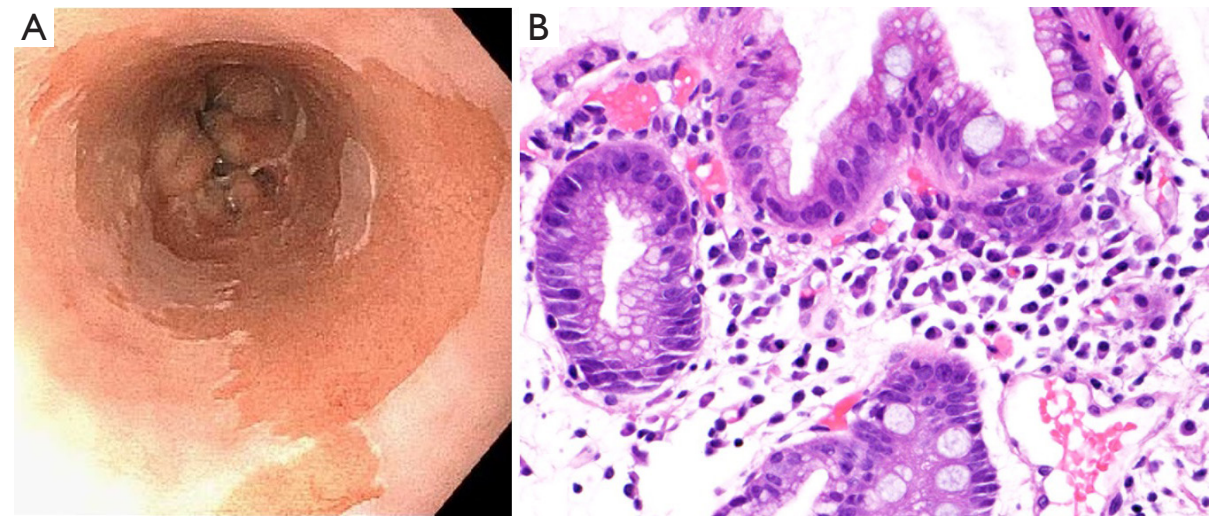

Figure $3 \mathrm{BE}$. (A) Endoscopic image of $\mathrm{BE}$ in an adult patient with evidence of salmon colored mucosa extending proximally into the esophagus. (B) Histology of BE in a pediatric patient includes columnar epithelium with IM and the presence of goblets cells (H\&E stain, 400× magnification). BE, Barrett's esophagus; IM, intestinal metaplasia.

surveillance is to detect dysplasia at an earlier stage. The degree of dysplasia (no dysplasia, low grade dysplasia, high grade dysplasia, adenocarcinoma) determines recommendations for surveillance intervals and the need for endoscopic eradication therapy (EET) $(42,43,45)$. Endoscopy is regarded as the gold standard for screening and is optimally performed utilizing high-resolution/high definition white light endoscopy to visualize mucosal detail $(42,43,45)$. Advanced imaging technologies for endoscopic surveillance have been developed in an attempt to improve detection. These include dye-based chromoendoscopy, electronic chromoendoscopy such as narrow-band imaging, volumetric laser endomicroscopy and confocal laser endomicroscopy $(43,50)$.

Less invasive diagnostic methods have been studied in $\mathrm{BE}$, including the uTNE and the Cytosponge Cell Collection Device. uTNE can be considered as an alternative method to conventional upper endoscopy for $\mathrm{BE}$ screening with comparable performance characteristics compared to endoscopy (sensitivity $98 \%$ and specificity $100 \%)(42,45,51)$. The Cytosponge is a well-tolerated device that obtains esophageal tissue samples for testing of protein biomarkers and has a $73 \%$ sensitivity and $94 \%$ specificity for the diagnosis of BE (42). The EsoCheck Cell Collection Device, a retractable balloon attached to a string that, when swallowed, gathers cell from the distal esophagus that can be used to detect DNA markers of BE (45). Another novel device is the wide-area transepithelial sampling with three-dimensional computer-assisted analysis (WATS-3D). WATS-3D utilizes a brush to sample layers of the esophageal epithelium. When used in addition to endoscopic forceps biopsy, WATS-3D increased the overall detection of BE in adults (52).

\section{Treatment and management}

Among patients with BE, symptoms of GER should be managed with use of daily PPI therapy to maximize acid suppression and treat esophagitis, unless symptoms require twice daily dosing for reflux symptom control $(42,43,45)$. Moreover, studies have shown that use of PPI therapy decreased the risk of neoplastic progression in patients with BE $(25,53)$. Long-term exposure ( $>3$ years) of PPI therapy was associated with a lower risk of EAC and/or BE with high grade dysplasia (53). While it has been proposed that long term PPI use can potentially lead to the development of gastric adenocarcinoma or gastric neuroendocrine tumors through mechanisms that promote pan-colonization of $H$. pylori or hypergastrinemia, respectively, current studies have not supported an association of long term PPI use with gastric cancers, neuroendocrine tumors, or premalignant changes (54-57). In a randomized, double blind placebo controlled trial that followed participants over a medium 3-year period, it was found that pantoprazole was not associated with long-term harmful outcomes with the exception of enteric infections (58). Thus, in cases where PPI use is clinically needed, the benefits outweigh the risks.

EET plays an important role in the management of BE, dysplasia, and early EAC. Patients with evidence of nodularity or visible abnormalities in the BE segment 
should undergo endoscopic mucosal resection (EMR) of the lesion as both a diagnostic and therapeutic maneuver $(42,43)$. Endoscopic ablative therapies are not recommended in patients with nondysplastic BE due to the low risk of progression to EAC $(42,43)$. However, ablative therapies are considered the preferred treatment strategy for patients with confirmed low grade dysplasia or high grade dysplasia (42). Radiofrequency ablation (RFA) is the most commonly used ablative modality, with high rates of complete eradication of intestinal metaplasia (CEIM) and dysplasia $(42,44,59)$. Cryotherapy involves rapid freezing and slow thawing of tissue resulting in cellular injury through the use of various cryogens and can be used in BE refractory to RFA (60). These endoscopic eradication therapies have not been described for the use of $\mathrm{BE}$ in pediatric patients.

\section{Esophageal neoplasms}

\section{Epidemiology and clinical presentation}

Esophageal neoplasms are extremely rare in children. EAC and esophageal squamous cell carcinoma (ESCC) comprise the majority of childhood esophageal malignant neoplasms, however several benign neoplasms have been reported. Esophageal neoplasms in children are summarized in Table 1 (61-75). Caustic ingestion, tobacco use, and history of esophageal atresia repair are considered risk factors for both EAC and ESCC $(61,62)$. Both EAC and ESCC, found near or at an anastomotic site, are seen as long-term sequela ( $>30$ years) after reconstruction of esophageal atresia (76-78). It is speculated that after repair, long-standing GERD, esophageal stasis, and mucosal damage lead to the development of these malignancies (76). GER and BE are considered risk factors for EAC $(61,79)$. Approximately $60 \%$ of pediatric patients with EAC have pre-existing conditions associated with GER, such as hiatal hernia, esophageal atresia repair, and obesity (62). In a case series of fourteen pediatric patients with EAC, 78\% of cases were associated with $\mathrm{BE}$, suggesting that, similar to adults, $\mathrm{BE}$ is a strong risk factor for the development of EAC (61).

The most common presenting symptoms of esophageal carcinomas and other neoplasms in children are progressive dysphagia and weight loss (Table 1) (61-75). In adults, EAC predominantly develops in the lower one-third of the esophagus. However, in approximately $40 \%$ of pediatric EAC cases, the lesion can be found above the distal esophagus $(61,63)$.

\section{Diagnosis}

Survival is dependent on various factors including disease stage, prompt diagnosis, growth pattern, tumor location, and rate of growth $(62,64)$. Better outcomes for EAC are seen with surveillance endoscopy and early detection of the disease (45). In a study examining adult patients with $\mathrm{BE}$ that developed EAC, $49.3 \%$ of patients were in BE surveillance programs and diagnosed by endoscopy. These patients were more likely to be diagnosed at an early stage, have longer survival and have lower cancer-related mortality (80).

Pediatric diagnostic and treatment guidelines for esophageal cancer are not well established due to the rarity of esophageal neoplasms in childhood, thus we focus on review of adult literature and studies. In patients with suspected esophageal neoplasms, diagnosis typically combines information from imaging of the thorax, upper endoscopy or other procedural intervention to obtain histology, and a multidisciplinary evaluation by surgery and oncology specialties. Diagnosis is confirmed by histological review of biopsy tissue (61).

\section{Treatment and management}

Surgical esophagectomy is considered the treatment of choice for submucosal cancers, poorly differentiated cancers, or cancers with a high risk of lymph node metastasis $(42,81)$. Less invasive surgical resection techniques can be considered. In a retrospective study comparing conventional open esophagectomy (OE), minimally invasive esophagectomy (MIE), and Hybrid esophagectomy, there was no significant difference between the three techniques for the outcomes of lymph nodes retrieved, resection margin-positive disease, and tumor recurrence (82).

Other treatment options in adults include adjuvant chemotherapy and EET (81). EET, which includes EMR and endoscopic ablative techniques such as RFA and cryotherapy, has demonstrated safety and efficacy for eradication of IM and disease remission with few adverse effects $(59,81,83,84)$. Early data in adults suggests the use of immunotherapies as possible treatment options for advanced gastrointestinal (GI) cancers, although there are limited approvals to date (85-87). These types of therapeutics include immune checkpoint inhibitors such as ipilimumab (CTLA-4 inhibitors), nivolumab and pembrolizumab (PD-1/PD-L1 inhibitor), and tyrosine kinase inhibitors targeting human epidermal growth factor 


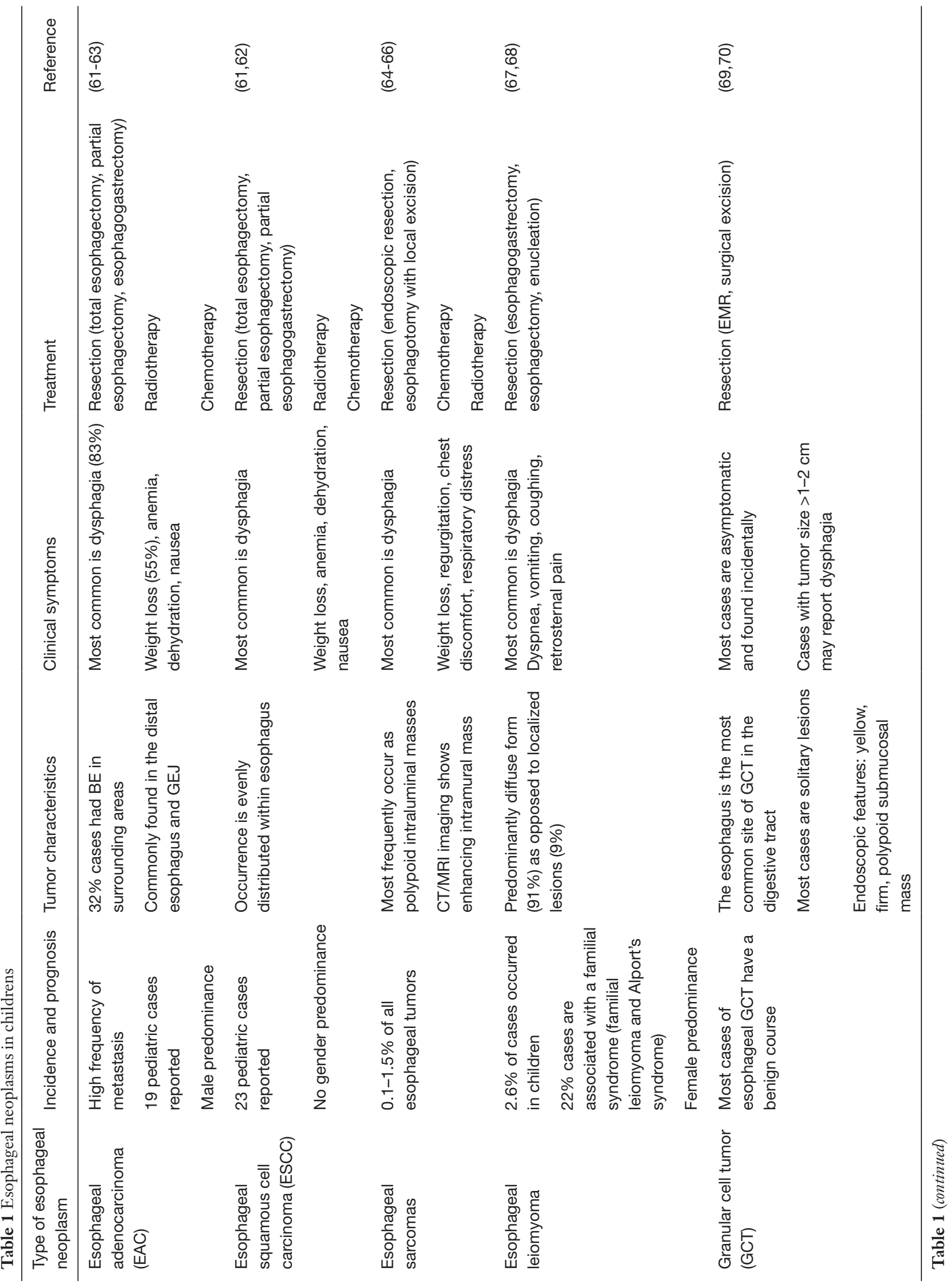


Translational Gastroenterology and Hepatology, 2021

Page 9 of 14

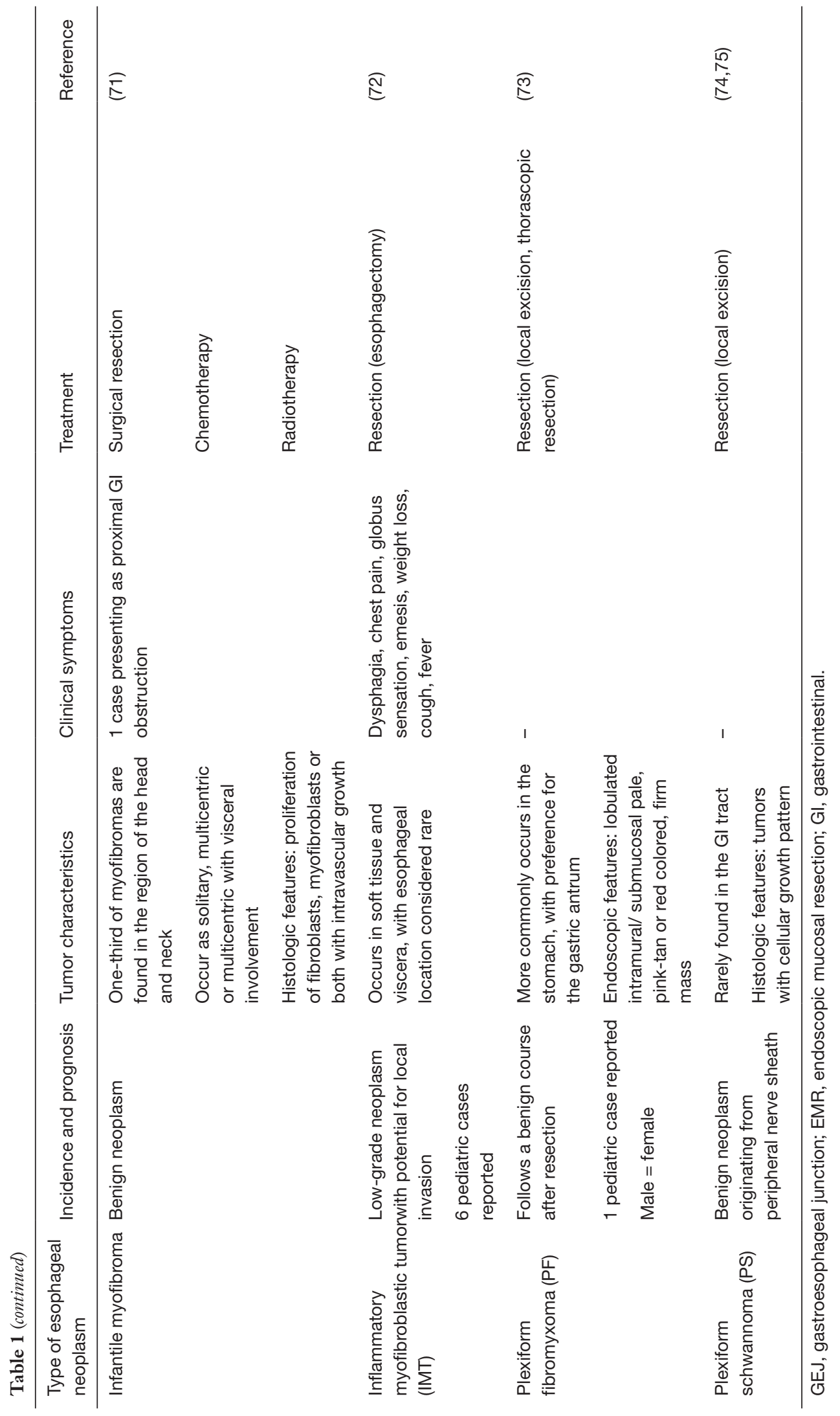


receptor 2 (HER2) (85-87). There is an active phase1 study being conducted at the University of Oxford evaluating the combination of an ATR inhibitor with chemoradiotherapy in esophageal cancers in patients 16 years of age or older (ClinicalTrials.gov. NCT03641547). Table 1 lists the treatment strategies that have been reported in prior case reports, however no common treatment strategies are established in children.

Although esophageal neoplasms in childhood are rare, they should be considered in the assessment of pediatric patients presenting with symptoms of progressive dysphagia and weight loss or with underlying risk factors.

\section{Conclusions}

EoE is the most common pediatric esophageal inflammatory condition, second to GERD. The EoE field is rapidly evolving as the incidence and prevalence continue to rise. Since EoE often starts in childhood and progresses to adulthood, new studies and clinical guidelines involve joint effort from pediatric and adult specialists. In contrast, BE and esophageal neoplasms rarely occur in childhood. The relationship between a chronic inflammatory condition like $\mathrm{EoE}$ to $\mathrm{BE}$ and/or esophageal neoplasms is uncharted. However, increased awareness of and diagnostic screening for EoE in the pediatric population, might have some indirect effect on detecting $\mathrm{BE}$ and incipient esophageal neoplasms. Thus, future observational studies will be essential to exploring the relationships between these diseases.

\section{Acknowledgments}

Funding: None.

\section{Footnote}

Provenance and Peer Review: This article was commissioned by the Guest Editors (Eduardo Perez, Samir Pandya, and Matthew S. Clifton) for the series "Current Topics in Pediatric General Surgery" published in Translational Gastroenterology and Hepatology. The article has undergone external peer review.

Reporting Checklist: The authors have completed the Narrative Review reporting checklist. Available at http:// dx.doi.org/10.21037/tgh-20-223
Conflicts of Interest: All authors have completed the ICMJE uniform disclosure form (available at http://dx.doi. org/10.21037/tgh-20-223). The series "Current Topics in Pediatric General Surgery" was commissioned by the editorial office without any funding or sponsorship. The authors have no other conflicts of interest to declare.

Ethical Statement: The authors are accountable for all aspects of the work in ensuring that questions related to the accuracy or integrity of any part of the work are appropriately investigated and resolved.

Open Access Statement: This is an Open Access article distributed in accordance with the Creative Commons Attribution-NonCommercial-NoDerivs 4.0 International License (CC BY-NC-ND 4.0), which permits the noncommercial replication and distribution of the article with the strict proviso that no changes or edits are made and the original work is properly cited (including links to both the formal publication through the relevant DOI and the license). See: https://creativecommons.org/licenses/by-nc-nd/4.0/.

\section{References}

1. Furuta GT, Katzka DA. Eosinophilic esophagitis. N Engl J Med 2015;373:1640-8.

2. Dellon ES, Gonsalves N, Hirano I, et al. ACG clinical guideline: evidenced based approach to the diagnosis and management of esophageal eosinophilia and eosinophilic esophagitis (EoE). Am J Gastroenterol 2013;108:679-92; quiz 693.

3. Cheng E, Souza RF, Spechler SJ. Tissue remodeling in eosinophilic esophagitis. Am J Physiol Gastrointest Liver Physiol 2012;303:G1175-87.

4. Gonsalves N. Distinct features in the clinical presentations of eosinophilic esophagitis in children and adults: is this the same disease? Dig Dis 2014;32:89-92.

5. Dellon ES, Liacouras CA, Molina-Infante J, et al. Updated international consensus diagnostic criteria for eosinophilic esophagitis: proceedings of the AGREE Conference. Gastroenterology 2018;155:1022-33.e10.

6. Sperry SL, Woosley JT, Shaheen NJ, et al. Influence of race and gender on the presentation of eosinophilic esophagitis. Am J Gastroenterol 2012;107:215-21.

7. Dellon ES, Jensen ET, Martin CF, et al. Prevalence of eosinophilic esophagitis in the United States. Clin Gastroenterol Hepatol 2014;12:589-96 e1. 
8. Gonsalves NP, Aceves SS. Diagnosis and treatment of eosinophilic esophagitis. J Allergy Clin Immunol 2020;145:1-7.

9. Dellon ES, Kim HP, Sperry SL, et al. A phenotypic analysis shows that eosinophilic esophagitis is a progressive fibrostenotic disease. Gastrointest Endosc 2014;79:577-85.e4.

10. Martin LJ, Franciosi JP, Collins MH, et al. Pediatric Eosinophilic Esophagitis Symptom Scores (PEESS v2.0) identify histologic and molecular correlates of the key clinical features of disease. J Allergy Clin Immunol 2015;135:1519-28.e8.

11. Spergel JM, Brown-Whitehorn TF, Beausoleil JL, et al. 14 years of eosinophilic esophagitis: clinical features and prognosis. J Pediatr Gastroenterol Nutr 2009;48:30-6.

12. Hirano I, Moy N, Heckman MG, et al. Endoscopic assessment of the oesophageal features of eosinophilic oesophagitis: validation of a novel classification and grading system. Gut 2013;62:489-95.

13. Lucendo AJ, Pascual-Turrion JM, Navarro M, et al. Endoscopic, bioptic, and manometric findings in eosinophilic esophagitis before and after steroid therapy: a case series. Endoscopy 2007;39:765-71.

14. Gonsalves N. Clinical presentation and approach to dietary management of eosinophilic esophagitis. Gastroenterol Hepatol (N Y) 2018;14:706-12.

15. Aceves SS. Tissue remodeling in patients with eosinophilic esophagitis: what lies beneath the surface? J Allergy Clin Immunol 2011;128:1047-9.

16. Wang J, Park JY, Huang R, et al. Obtaining adequate lamina propria for subepithelial fibrosis evaluation in pediatric eosinophilic esophagitis. Gastrointest Endosc 2018;87:1207-14.e3.

17. Furuta GT, Kagalwalla AF, Lee JJ, et al. The oesophageal string test: a novel, minimally invasive method measures mucosal inflammation in eosinophilic oesophagitis. Gut 2013;62:1395-405.

18. Ackerman SJ, Kagalwalla AF, Hirano I, et al. One-hour esophageal string test: a nonendoscopic minimally invasive test that accurately detects disease activity in eosinophilic esophagitis. Am J Gastroenterol 2019;114:1614-25.

19. Friedlander JA, DeBoer EM, Soden JS, et al. Unsedated transnasal esophagoscopy for monitoring therapy in pediatric eosinophilic esophagitis. Gastrointest Endosc 2016;83:299-306.e1.

20. Godwin B, Wilkins B, Muir AB. EoE disease monitoring: where we are and where we are going. Ann Allergy Asthma Immunol 2020;124:240-7.
21. Katzka DA, Smyrk TC, Alexander JA, et al. Accuracy and safety of the cytosponge for assessing histologic activity in eosinophilic esophagitis: a two-center study. Am J Gastroenterol 2017;112:1538-44.

22. Hirano I, Pandolfino JE, Boeckxstaens GE. Functional lumen imaging probe for the management of esophageal disorders: expert review from the clinical practice updates committee of the AGA Institute. Clin Gastroenterol Hepatol 2017;15:325-34.

23. Carlson DA. Functional lumen imaging probe: the FLIP side of esophageal disease. Curr Opin Gastroenterol 2016;32:310-8.

24. Carlson DA, Lin Z, Hirano I, et al. Evaluation of esophageal distensibility in eosinophilic esophagitis: an update and comparison of functional lumen imaging probe analytic methods. Neurogastroenterol Motil 2016;28:1844-53.

25. Kastelein F, Spaander MC, Steyerberg EW, et al. Proton pump inhibitors reduce the risk of neoplastic progression in patients with Barrett's esophagus. Clin Gastroenterol Hepatol 2013;11:382-8.

26. Dohil R, Newbury RO, Aceves S. Transient PPI responsive esophageal eosinophilia may be a clinical subphenotype of pediatric eosinophilic esophagitis. Dig Dis Sci 2012;57:1413-9.

27. Hirano I, Dellon ES, Hamilton JD, et al. Efficacy of dupilumab in a phase 2 randomized trial of adults with active eosinophilic esophagitis. Gastroenterology 2020;158:111-22.e10.

28. Lucendo AJ, Miehlke S, Schlag C, et al. Efficacy of budesonide orodispersible tablets as induction therapy for eosinophilic esophagitis in a randomized placebocontrolled trial. Gastroenterology 2019;157:74-86.e15.

29. Lucendo AJ, Arias A, Molina-Infante J. Efficacy of proton pump inhibitor drugs for inducing clinical and histologic remission in patients with symptomatic esophageal eosinophilia: a systematic review and meta-analysis. Clin Gastroenterol Hepatol 2016;14:13-22.e1.

30. Hirano I, Chan ES, Rank MA, et al. AGA institute and the joint task force on allergy-immunology practice parameters clinical guidelines for the management of eosinophilic esophagitis. Ann Allergy Asthma Immunol 2020;124:416-23.

31. Molina-Infante J, Bredenoord AJ, Cheng E, et al. Proton pump inhibitor-responsive oesophageal eosinophilia: an entity challenging current diagnostic criteria for eosinophilic oesophagitis. Gut 2016;65:524-31.

32. Cheng E, Zhang X, Huo X, et al. Omeprazole blocks 
eotaxin-3 expression by oesophageal squamous cells from patients with eosinophilic oesophagitis and GORD. Gut 2013;62:824-32.

33. Cheng E. Translating new developments in eosinophilic esophagitis pathogenesis into clinical practice. Curr Treat Options Gastroenterol 2015;13:30-46.

34. Kelly KJ, Lazenby AJ, Rowe PC, et al. Eosinophilic esophagitis attributed to gastroesophageal reflux: improvement with an amino acid-based formula. Gastroenterology 1995;109:1503-12.

35. Arias A, Gonzalez-Cervera J, Tenias JM, et al. Efficacy of dietary interventions for inducing histologic remission in patients with eosinophilic esophagitis: a systematic review and meta-analysis. Gastroenterology 2014;146:1639-48.

36. Kagalwalla AF, Sentongo TA, Ritz S, et al. Effect of sixfood elimination diet on clinical and histologic outcomes in eosinophilic esophagitis. Clin Gastroenterol Hepatol 2006;4:1097-102.

37. Lucendo AJ, Molina-Infante J. Esophageal dilation in eosinophilic esophagitis: risks, benefits, and when to do it. Curr Opin Gastroenterol 2018;34:226-32.

38. Dougherty M, Runge TM, Eluri S, et al. Esophageal dilation with either bougie or balloon technique as a treatment for eosinophilic esophagitis: a systematic review and meta-analysis. Gastrointest Endosc 2017;86:581-91.e3.

39. Hirano I, Furuta GT. Approaches and challenges to management of pediatric and adult patients with eosinophilic esophagitis. Gastroenterology 2020;158:840-51.

40. O'Shea KM, Aceves SS, Dellon ES, et al. Pathophysiology of Eosinophilic Esophagitis. Gastroenterology 2018;154:333-45.

41. Harish A, Schwartz SA. Targeted anti-IL-5 therapies and future therapeutics for hypereosinophilic syndrome and rare eosinophilic conditions. Clin Rev Allergy Immunol 2020;59:231-47.

42. Shaheen NJ, Falk GW, Iyer PG, et al. ACG clinical guideline: diagnosis and management of Barrett's esophagus. Am J Gastroenterol 2016;111:30-50; quiz 51.

43. Clermont M, Falk GW. Clinical guidelines update on the diagnosis and management of Barrett's esophagus. Dig Dis Sci 2018;63:2122-8.

44. Reed CC, Shaheen NJ. Management of Barrett esophagus following radiofrequency ablation. Gastroenterol Hepatol (N Y) 2019;15:377-86

45. Singh T, Sanghi V, Thota PN. Current management of Barrett esophagus and esophageal adenocarcinoma. Cleve
Clin J Med 2019;86:724-32.

46. Jeurnink SM, van Herwaarden-Lindeboom MY, Siersema PD, et al. Barrett's esophagus in children: does it need more attention? Dig Liver Dis 2011;43:682-7.

47. Putra J, Arva NC, Tan SY, et al. Barrett esophagus and intestinal metaplasia of the gastroesophageal junction in children: a clinicopathologic study. J Pediatr Gastroenterol Nutr 2020;70:562-7.

48. Chak A, Lee T, Kinnard MF, et al. Familial aggregation of Barrett's oesophagus, oesophageal adenocarcinoma, and oesophagogastric junctional adenocarcinoma in Caucasian adults. Gut 2002;51:323-8.

49. Harrison R, Perry I, Haddadin W, et al. Detection of intestinal metaplasia in Barrett's esophagus: an observational comparator study suggests the need for a minimum of eight biopsies. Am J Gastroenterol 2007;102:1154-61.

50. ASGE Technology Committee, Thosani N, Abu Dayyeh BK, et al. ASGE Technology Committee systematic review and meta-analysis assessing the ASGE Preservation and Incorporation of Valuable Endoscopic Innovations thresholds for adopting real-time imaging-assisted endoscopic targeted biopsy during endoscopic surveillance of Barrett's esophagus. Gastrointest Endosc 2016;83:68498.e7.

51. Shariff MK, Bird-Lieberman EL, O'Donovan M, et al. Randomized crossover study comparing efficacy of transnasal endoscopy with that of standard endoscopy to detect Barrett's esophagus. Gastrointest Endosc 2012;75:954-61.

52. Gross SA, Smith MS, Kaul V, et al. Increased detection of Barrett's esophagus and esophageal dysplasia with adjunctive use of wide-area transepithelial sample with three-dimensional computer-assisted analysis (WATS). United European Gastroenterol J 2018;6:529-35.

53. Singh S, Garg SK, Singh PP, et al. Acid-suppressive medications and risk of oesophageal adenocarcinoma in patients with Barrett's oesophagus: a systematic review and meta-analysis. Gut 2014;63:1229-37.

54. Ko Y, Tang J, Sanagapalli S, et al. Safety of proton pump inhibitors and risk of gastric cancers: review of literature and pathophysiological mechanisms. Expert Opin Drug Saf 2016;15:53-63.

55. Freedberg DE, Kim LS, Yang YX. The risks and benefits of long-term use of proton pump inhibitors: expert review and best practice advice from the American Gastroenterological Association. Gastroenterology 2017;152:706-15. 
56. Attwood SE, Ell C, Galmiche JP, et al. Long-term safety of proton pump inhibitor therapy assessed under controlled, randomised clinical trial conditions: data from the SOPRAN and LOTUS studies. Aliment Pharmacol Ther 2015;41:1162-74.

57. Song H, Zhu J, Lu D. Long-term proton pump inhibitor (PPI) use and the development of gastric pre-malignant lesions. Cochrane Database Syst Rev 2014;(12):CD010623.

58. Moayyedi P, Eikelboom JW, Bosch J, et al. Safety of proton pump inhibitors based on a large, multi-year, randomized trial of patients receiving rivaroxaban or aspirin. Gastroenterology 2019;157:682-91.e2.

59. Orman ES, Li N, Shaheen NJ. Efficacy and durability of radiofrequency ablation for Barrett's esophagus: systematic review and meta-analysis. Clin Gastroenterol Hepatol 2013;11:1245-55.

60. Singh T, Sanaka MR, Thota PN. Endoscopic therapy for Barrett's esophagus and early esophageal cancer: where do we go from here? World J Gastrointest Endosc 2018;10:165-74.

61. Issaivanan M, Redner A, Weinstein T, et al. Esophageal carcinoma in children and adolescents. J Pediatr Hematol Oncol 2012;34:63-7.

62. Theilen TM, Chou AJ, Klimstra DS, et al. Esophageal adenocarcinoma and squamous cell carcinoma in children and adolescents: report of 3 cases and comprehensive literature review. J Pediatr Surg Case Rep 2016;5:23-9.

63. Hwang JY, Lee YJ, Chun P, et al. Esophageal adenocarcinoma and Barrett esophagus in a neurologically impaired teenager. Pediatr Int 2016;58:1235-8.

64. Patricia S, Saikat D, Rajesh B, et al. Rare cause of stricture esophagus-sarcoma: a case report and review of the literature. Case Rep Gastrointest Med 2011;2011:192423.

65. Antón-Pacheco J, Cano I, Cuadros J, et al. Synovial sarcoma of the esophagus. J Pediatr Surg 1996;31:1703-5.

66. Perch SJ, Soffen EM, Whittington R, et al. Esophageal sarcomas. J Surg Oncol 1991;48:194-8.

67. Al-Bassam A, Al-Rabeeah A, Fouda-Neel K, et al. Leiomyoma of the esophagus and bronchus in a child. Pediatr Surg Int 1998;13:45-7.

68. Bourque MD, Spigland N, Bensoussan AL, et al. Esophageal leiomyoma in children: two case reports and review of the literature. J Pediatr Surg 1989;24:1103-7.

69. Buratti S, Savides TJ, Newbury RO, et al. Granular cell tumor of the esophagus: report of a pediatric case and literature review. J Pediatr Gastroenterol Nutr 2004;38:97-101.

70. Lee JS, Ko KO, Lim JW, et al. Granular cell tumor of the esophagus in an adolescent. Korean J Pediatr 2016;59:S88-91.

71. Wilson M, Emil S, Cowan K, et al. Infantile myofibromas obstructing opposite ends of the gastrointestinal tract. J Pediatr Surg 2013;48:449-53.

72. Dousek R, Tuma J, Planka L, et al. Inflammatory myofibroblastic tumor of the esophagus in childhood: a case report and a review of the literature. J Pediatr Hematol Oncol 2015;37:e121-4.

73. Duckworth LV, Gonzalez RS, Martelli M, et al. Plexiform fibromyxoma: report of two pediatric cases and review of the literature. Pediatr Dev Pathol 2014;17:21-7.

74. Agaram NP, Prakash S, Antonescu CR. Deep-seated plexiform schwannoma: a pathologic study of 16 cases and comparative analysis with the superficial variety. Am J Surg Pathol 2005;29:1042-8.

75. Retrosi G, Nanni L, Ricci R, et al. Plexiform schwannoma of the esophagus in a child with neurofibromatosis type 2 . J Pediatr Surg 2009;44:1458-61.

76. Vergouwe FW, Gottrand M, Wijnhoven BP, et al. Four cancer cases after esophageal atresia repair: time to start screening the upper gastrointestinal tract. World J Gastroenterol 2018;24:1056-62.

77. Deurloo JA, van Lanschot JJ, Drillenburg P, et al. Esophageal squamous cell carcinoma 38 years after primary repair of esophageal atresia. J Pediatr Surg 2001;36:629-30.

78. Krishnan U, Mousa H, Dall'Oglio L, et al. ESPGHANNASPGHAN guidelines for the evaluation and treatment of gastrointestinal and nutritional complications in children with esophageal atresia-tracheoesophageal fistula. J Pediatr Gastroenterol Nutr 2016;63:550-70.

79. Childhood Esophageal Cancer Treatment (PDQ®)Health Professional Version. Bethesda: PDQ Cancer Information Summaries, 2019.

80. El-Serag HB, Naik AD, Duan Z, et al. Surveillance endoscopy is associated with improved outcomes of oesophageal adenocarcinoma detected in patients with Barrett's oesophagus. Gut 2016;65:1252-60.

81. Standards of Practice Committee, Wani S, Qumseya B, et al. Endoscopic eradication therapy for patients with Barrett's esophagus-associated dysplasia and intramucosal cancer. Gastrointest Endosc 2018;87:907-31.e9.

82. Khan M, Muzaffar A, Syed AA, et al. Changes in oncological outcomes: comparison of the conventional and minimally invasive esophagectomy, a single institution experience. Updates Surg 2016;68:343-9.

83. Frei N, Frei R, Semadeni GM, et al. Endoscopic treatment 
of early Barrett's adenocarcinoma and dysplasia: focus on submucosal cancer. Digestion 2019;99:293-300.

84. Pech O, Behrens A, May A, et al. Long-term results and risk factor analysis for recurrence after curative endoscopic therapy in 349 patients with high-grade intraepithelial neoplasia and mucosal adenocarcinoma in Barrett's oesophagus. Gut 2008;57:1200-6.

85. Park R, Williamson $\mathrm{S}$, Kasi A, et al. Immune therapeutics in the treatment of advanced gastric and esophageal cancer. Anticancer Res 2018;38:5569-80.

doi: $10.21037 / \operatorname{tgh}-20-223$

Cite this article as: Medina AL, Troendle DM, Park JY, Thaker A, Dunbar KB, Cheng E. Eosinophilic esophagitis, Barrett's esophagus and esophageal neoplasms in the pediatric patient: a narrative review. Transl Gastroenterol Hepatol 2021;6:32.
86. Hassan MS, Williams F, Awasthi N, et al. Combination effect of lapatinib with foretinib in HER2 and MET coactivated experimental esophageal adenocarcinoma. Sci Rep 2019;9:17608.

87. Chuang J, Chao J, Hendifar A, et al. Checkpoint inhibition in advanced gastroesophageal cancer: clinical trial data, molecular subtyping, predictive biomarkers, and the potential of combination therapies. Transl Gastroenterol Hepatol 2019;4:63. 